recommendations,

eight are new,

seven unaltered

and the remaining

17 were amended

Anne B Chang MPHTM, PhD, FRACP 1,2

Scott C Bell MBBS, MD, FRACP ${ }^{3}$

Paul J Torzillo MBBS, FRACP, FFICM ${ }^{4}$

Paul T King MBBS, PhD, FRACP ${ }^{5,6}$

Graeme P Maguire MPHTM, PhD, FRACP

Catherine A Byrnes

MD, FRACP 8,9

Anne E Holland BAppSc(Physiotherapy) $\mathrm{PhD}^{10}$

Peter O'Mara GradDipRuralGenPrac FRACGP ${ }^{12}$

Keith Grimwood MBChB, MD, FRACP ${ }^{33,14}$

and the extended voting group*

1 Queensland Children's Medical Research Institute Brisbane, QLD.

2 Menzies School of Health Research, Darwin, NT.

3 Prince Charles Hospital, Brisbane, QLD.

4 Royal Prince Alfred Hospital Medical Centre, Sydney, NSW.

5 Monash Medical Centre, Melbourne, VIC.

6 Monash University. Melbourne, VIC

7 Baker IDI Central Australia Alice Springs, NT.

8 University of Auckland Auckland, NZ.

9 Starship Children's Hospital, Auckland, NZ.

10 Alfred Health, Mebourne, VIC.

11 La Trobe University, Melbourne, VIC.

12 University of Newcastle. Newcastle, NSW.

13 Griffith University, Gold Coast, QLD. 14 Gold Coast University Hospital, Gold Coast, QLD.

annechang@ ausdoctors.net

\title{
Chronic suppurative lung disease and bronchiectasis in children and adults in Australia and New Zealand
}

Guidelines on managing chronic suppurative lung disease (CSLD) and bronchiectasis (unrelated to cystic fibrosis [CF]) in Australian Indigenous children initiated in $2002^{\prime}$ were extended to include Indigenous adults in $2008^{2}$ and children and adults living in urban areas of Australia and New Zealand in 2010. ${ }^{3}$ Here, we present an updated guideline relevant for all sections of the community. The recommendations in this guideline are targeted principally to primary and secondary care, and are not intended for individualised specialist care. As with all guidelines, they are not a substitute for sound clinical judgement, particularly when investigating and treating such a phenotypically heterogeneous condition as bronchiectasis. ${ }^{4}$

\section{Key updates}

An increasing trend in the health burden of CSLD and bronchiectasis is recognised in both Indigenous and non-Indigenous settings in Australia, New Zealand and worldwide. ${ }^{3,5-7}$ Some affluent countries report childhood fatalities, ${ }^{7}$ and there is a growing appreciation of the economic cost. ${ }^{5}$ Misdiagnosis or coexistence of bronchiectasis with other chronic respiratory diseases is also recognised increasingly. When these comorbidities are present, the prognosis is worse; for example, mortality increases in those with both chronic obstructive pulmonary disease (COPD) and bronchiectasis (hazard ratio, 2.54; 95\% CI, 1.16-5.56). ${ }^{6}$ As many as $9 \%$ of newly referred children with chronic cough in Australia have bronchiectasis, ${ }^{8}$ and $40 \%$ of newly referred adults with difficult asthma have bronchiectasis. ${ }^{9}$ As effective management influences prognosis and quality of life, ${ }^{10}$ a heightened vigilance by health professionals is needed to ensure an early diagnosis is made and treatment is optimised.

There is still a paucity of data and clinical trials on bronchiectasis, but encouraging trends of better evidence have emerged. These include studies related to defining CSLD in children, ${ }^{10,11}$ airway clearance, rehabilitation, and use of nebulised and long-term maintenance antibiotics to prevent exacerbations. These studies (obtained through systematic searches ${ }^{12}$ ) formed the basis for our updated recommendations. When evidence was lacking, Australian and New Zealand experts (the writing group) developed the recommendations, which were further informed by the voting group using a modified Delphi process and the GRADE (grading of recommendations assessment, development and evaluation) system. ${ }^{13}$

Of the 32 recommendations, eight are new $(3,8,10,14$, $25,30-32)$, seven unaltered $(7,17-18,22-24,29)$ and the remaining 17 were amended. We refer readers to the Thoracic Society of Australia and New Zealand website for the full guidelines (http://www.thoracic.org.au/ professional-information/position-papers-guidelines/ bronchiectasis) including information about our guidelines development process, details of the systematic searches, evidence for the recommendations, implications of the strength of recommendations, suggested antibiotic regimens for management and updated references. ${ }^{12}$

\begin{tabular}{|c|c|c|c|}
\hline Number & Recommendation & $\begin{array}{l}\text { GRADE } \\
\text { category }\end{array}$ & $\begin{array}{c}\text { Evidence } \\
\text { level }\end{array}$ \\
\hline \multicolumn{4}{|c|}{ Definitions } \\
\hline \multirow[t]{4}{*}{1} & $\begin{array}{l}\text { a. Bronchiectasis is a clinical syndrome in a child or adult with the symptoms and/or signs } \\
\text { outlined below as well as characteristic radiographic features on chest high-resolution computed } \\
\text { tomography (c-HRCT). }\end{array}$ & Strong & - \\
\hline & $\begin{array}{l}\text { Symptoms and signs include recurrent wet or productive cough episodes ( } \geqslant 3 \text { per year), each } \\
\text { lasting for }>4 \text { weeks, with or without other features (for example, exertional dyspnoea, symptoms } \\
\text { of airway hyperresponsiveness, recurrent chest infections, growth failure, clubbing, hyperinflation or } \\
\text { chest wall deformity). }\end{array}$ & & \\
\hline & $\begin{array}{l}\text { In children, triggers for referral to a specialist include one or more of: } \\
\text { - persistent wet cough not responding to } 4 \text { weeks of antibiotics; } \\
\text { - } \geqslant 3 \text { episodes of chronic (> } 4 \text { weeks) wet cough per year responding to antibiotics; } \\
\text { - a chest radiograph abnormality persisting > } 6 \text { weeks after appropriate therapy. }\end{array}$ & & \\
\hline & $\begin{array}{l}\text { b. Chronic suppurative lung disease is a clinical syndrome in children with the symptoms and/or } \\
\text { signs outlined above, but who lack a radiographic diagnosis of bronchiectasis. }\end{array}$ & & \\
\hline
\end{tabular}




\begin{tabular}{ll}
\hline Number & Recommendation \\
\hline Investigations of a patient with CSLD or bronchiectasis &
\end{tabular}

2 a. Patients with symptoms and/or signs suggestive of bronchiectasis require a c-HRCT scan to confirm the diagnosis and to assess the severity and extent of bronchiectasis.

GRADE category

b. In children, seek specialist advice before ordering a c-HRCT scan; child-specific criteria should be used.

c. In both adults and children, a multidetector CT scan with HRCT reconstruction is the preferred technique to diagnose bronchiectasis. expiratory volume in 1 second $\left[\mathrm{FEV}_{1}\right]<30 \%$ predicted or requiring domiciliary oxygen) or whose sputum contains organisms atypical for COPD (ie, Aspergillus species, Pseudomonas aeruginosa or non-tuberculous mycobacteria).

Obtaining further history for specific underlying causes may determine subsequent investigation and management. This includes history of, or suggestive of:

- cystic fibrosis (family history, pancreatitis, chronic gastrointestinal symptoms, male infertility);

- underlying immune deficiency or ciliary dyskinesia (recurrent sinusitis, extrapulmonary infections, including discharging ears and severe dermatitis, and male infertility);

- recurrent aspiration (cough and/or choking with feeds or meals; after bariatric surgery; may be occult);

- an inhaled foreign body.

$5 \quad$ Perform or refer for baseline investigations. Minimum investigations are:

- full blood count and major immunoglobulin classes G, A, M, E;

Strong

Moderate

- sweat test in all children and selected adults (see full guidelines'2);

- culture of airway secretions, including specialised cultures for mycobacteria, particularly non-tuberculous mycobacteria in sputum-producing patients;

- spirometry and lung volumes (patients aged > 6 years); and serological tests for Aspergillus species.

In selected patients, other investigations should be considered (see full guidelines ${ }^{12}$ ).

6 Obtain further history to determine markers of severity, impact of illness, comorbidities and modifiable risk factors. History should include frequency of exacerbations and hospitalisations, degree of effort limitation, exposure to tobacco smoke and other pollutants, childhood history, and housing.

\section{Management}

$7 \quad$ Aim to optimise general wellbeing, symptom control, lung function and quality of life, and to reduce exacerbation frequency and prevent excessive decline in lung function. This may require intensive medical therapy.

8 Develop treatment plans for exacerbations for each patient, linking them to primary health care and specialist or hospital facilities. When appropriate, this includes individualised and self-initiated management action plans.

9 Base antibiotic selection on lower airway culture results (sputum, bronchoscopy washings [adults and older children] or bronchoalveolar lavage [young non-expectorating children]) when available, local antibiotic susceptibility patterns, clinical severity and patient tolerance, including allergy (Appendix).

When $P$. aeruginosa is first detected, consider discussion with a specialist in this field regarding suitability for eradication treatment.

$11 \quad$ In patients not requiring parenteral antibiotics for an acute exacerbation, oral antibiotics are prescribed for at least 10 days based on available airway microbiology results. Close follow-up to assess treatment response is necessary. Inadequate response should prompt repeat of lower airway cultures and assessment of whether parenteral antibiotic therapy and hospitalisation are needed.

13 Patients in whom oral antibiotic therapy for an acute exacerbation fails should receive intensive airway clearance strategies and parenteral antibiotics based on the latest lower airway culture results. Close follow-up is required.

a. In children, this requires supervised treatment for at least 10-14 days.

b. In adults, intravenous antibiotics should be administered for at least 5 days and often need to be followed by oral antibiotics. Conversion from intravenous to oral antibiotics depends on appropriate oral alternatives and whether effective adjunct therapies, such as airway clearance strategies, can be maintained in an ambulatory care setting and with ongoing outpatient review.

14 Long-term oral antibiotics should not be prescribed routinely. Macrolides (or other antibiotics) can be considered for a therapeutic trial over a limited period (eg, up to 12-24 months) in selected patients (eg, those with frequent exacerbations [ $\geqslant 3$ exacerbations and/or $\geqslant 2$ hospitalisations in the previous 12 months]).

Before commencing macrolide antibiotics:

- seek respiratory/infectious diseases specialist advice;

- ensure non-tuberculous mycobacteria infection is excluded in patients capable of providing a sputum specimen;

- perform electrocardiography in adults for assessment of QT interval corrected for heart rate. 


\begin{tabular}{|c|c|c|c|}
\hline Number & Recommendation & $\begin{array}{l}\text { GRADE } \\
\text { category }\end{array}$ & $\begin{array}{l}\text { Evidence } \\
\text { level }\end{array}$ \\
\hline 16 & $\begin{array}{l}\text { Inhaled and oral corticosteroids should not be prescribed routinely unless there is an established diagnosis of } \\
\text { coexisting asthma or COPD. }\end{array}$ & Strong & $\begin{array}{l}\text { Low*/ } \\
\text { moderate }\end{array}$ \\
\hline 17 & Inhaled bronchodilators should not be prescribed routinely but used only on an individual basis. & Strong & Low \\
\hline 18 & Recombinant human deoxyribonuclease is contraindicated in CSLD and bronchiectasis. & Strong & High \\
\hline 19 & $\begin{array}{l}\text { Mucoactive agents, including hypertonic saline and mannitol, are currently not recommended for routine use. } \\
\text { Consider a therapeutic trial in children and adults with frequent exacerbations. }\end{array}$ & Weak & Moderate \\
\hline 20 & $\begin{array}{l}\text { Airway clearance techniques are recommended and a respiratory physiotherapist's advice should be sought. } \\
\text { Individualise airway clearance therapy. }\end{array}$ & Strong & Moderate \\
\hline 21 & Adults with bronchiectasis and exercise limitation should receive pulmonary rehabilitation. & Strong & Moderate \\
\hline 22 & Regular physical activity is recommended for children and adults with CSLD or bronchiectasis. & Strong & Low \\
\hline 23 & Assess and optimise nutritional status. & Strong & Moderate \\
\hline 24 & Promote elimination of smoking, including second-hand smoke exposure. & Strong & High \\
\hline 25 & Promote avoidance of environmental airborne pollutants. & Strong & Low \\
\hline \multirow[t]{3}{*}{26} & $\begin{array}{l}\text { Regularly monitor and manage complications and comorbidities. When present, manage following standard } \\
\text { guidelines. }\end{array}$ & Strong & Moderate \\
\hline & $\begin{array}{l}\text { Regular review consists of at least an annual review in adults and 6-monthly review in children. A multidisciplinary } \\
\text { team is preferable, especially at the initial evaluation. }\end{array}$ & & \\
\hline & $\begin{array}{l}\text { Review includes: } \\
\text { - assessment of severity, which includes oximetry and spirometry; } \\
\text { - sputum culture (when available) for routine bacterial and annual mycobacterial culture; } \\
\text { - management of possible complications and comorbidities, particularly gastro-oesophageal reflux disease or } \\
\text { aspiration, reactive airway disease or asthma, COPD, otorhinolaryngeal disorders, urinary incontinence, mental } \\
\text { health and dental disease. Less commonly, patients require assessments for sleep disordered breathing and } \\
\text { cardiac complications; } \\
\text { - checking adherence to therapies and knowledge of disease processes and treatments. }\end{array}$ & & \\
\hline 27 & $\begin{array}{l}\text { Although surgery is not indicated normally, assessment by a multidisciplinary team expert in CSLD and } \\
\text { bronchiectasis care may be required in some circumstances. }\end{array}$ & Strong & Moderate \\
\hline \multicolumn{4}{|c|}{ Public health issues, prevention and appropriate health care delivery } \\
\hline 28 & $\begin{array}{l}\text { Vaccinate according to the National Immunisation Program Schedule. Ensure timely annual influenza vaccination } \\
\text { and that pneumococcal vaccines are administered following national guidelines. }\end{array}$ & Strong & Moderate \\
\hline 29 & $\begin{array}{l}\text { Coordinated care by health care providers is necessary. If bronchiectasis is suspected, specialist evaluation is } \\
\text { recommended to confirm the diagnosis, investigate the aetiology, assess severity and develop a management plan. } \\
\text { Patients with moderate or severe disease are best managed using a multidisciplinary approach to chronic care } \\
\text { with individualised case management. Clinical deterioration should prompt early referral to services with CSLD and } \\
\text { bronchiectasis expertise. }\end{array}$ & Strong & Low \\
\hline 30 & $\begin{array}{l}\text { Specialist review should be undertaken for patients with moderate disability or progressive lung disease. This } \\
\text { includes consideration for lung transplantation. }\end{array}$ & Strong & Low \\
\hline 31 & $\begin{array}{l}\text { Providing health care for Indigenous people in rural and remote regions requires flexible and adaptive arrangements. } \\
\text { However, this should not alter the objective of delivering best-practice treatment to this population. }\end{array}$ & Strong & Low \\
\hline 32 & $\begin{array}{l}\text { Given the high prevalence of CSLD and bronchiectasis in Indigenous Australians, Maori and Pacific Islander children } \\
\text { and adults, a high index of suspicion with early diagnostic investigation should be established, as well as best- } \\
\text { practice treatment. Interpreters and local health workers should be available for educating patients about the } \\
\text { disease and its management. }\end{array}$ & Strong & Moderate \\
\hline
\end{tabular}

\section{*Extended voting group (alphabetical order)}

Jenny Alison (University of Sydney, Sydney), Chris Cull (lay consumer, Brisbane), Bart Currie (Menzies School of Health Research, Darwin), Inge Gardner (lay consumer, Darwin), Peter Holmes (Monash Medical Centre, Melbourne), Cameron Hunter (Royal Hobart Hospital, Hobart), John Kolbe (Auckland University, Auckland, NZ), Carolyn Maclennan (Flinders University, Adelaide), Malcolm McDonald (James Cook University, Cairns), Peter Morris (Menzies School of Health Research, Darwin), Caroline Nicolson (Alfred Hospital, Melbourne), Helen Petsky (Royal Children's Hospital, Brisbane), Naveen Pillarisetti (Starship Children's Hospital, Auckland, NZ), Emma Reynolds (Starship Children's Hospital, Auckland, NZ), David Serisier (Mater Adult Hospital, Brisbane), Frank Thein (Box Hill Hospital, Melbourne), Peter van Asperen (Children's Hospital at Westmead, Sydney), Lesley Voss (Starship Children's Hospital, Auckland, NZ), Conroy Wong (Middlemore Hospital, Auckland, NZ).
Acknowledgements: This manuscript has been endorsed by the Thoracic Society of Australia and New Zealand. Costs of meetings were funded by the National Health and Medical Research Council (NHMRC) Centre for Research Excellence in Lung Health of Aboriginal and Torres Strait Islander Children (grant 1040830). Anne Chang is funded by an NHMRC practitioner fellowship (grant 1058213). Graeme Maguire is supported by an NHMRC practitioner fellowship (grant 1046563) and the Margaret Ross Chair in Indigenous Health.

Competing interests: No relevant disclosures.

Provenance: Not commissioned; externally peer reviewed. 
1 Chang AB, Grimwood K, Mulholland EK, Torzillo PJ; Working Group on Indigenous Paediatric Respiratory Health. Bronchiectasis in Indigenous children in remote Australian communities [position statement]. Med J Aust 2002; 177: 200-204.

2 Chang AB, Grimwood K, Macguire G, et al. Management of bronchiectasis and chronic suppurative lung disease in Indigenous children and adults from rural and remote Australian communities [position statement]. Med J Aust 2008; 189: 386-393.

3 Chang AB, Bell SC, Byrnes CA, et al. Chronic suppurative lung disease and bronchiectasis in children and adults in Australian and New Zealand. A position statement from the Thoracic Society of Australia and New Zealand and the Australian Lung Foundation. Med J Aust 2010; 193: 356-365.

4 King PT, Holdsworth SR, Farmer M, et al. Phenotypes of adult bronchiectasis: onset of productive cough in childhood and adulthood. COPD 2009; 6: 130-136.

5 Ringshausen FC, de Roux A, Pletz MW, et al. Bronchiectasisassociated hospitalizations in Germany, 2005-2011: a population-based study of disease burden and trends. PLOS One 2013; 8: e71109.

6 Martínez-García MA, de la Rosa Carillo D, Soler-Cataluña $\mathrm{JJ}$, et al. Prognostic value of bronchiectasis in patients with moderate-to-severe chronic obstructive pulmonary disease. Am J Respir Crit Care Med 2013; 187: 823-831.
7 Roberts HJ, Hubbard R. Trends in bronchiectasis mortality in England and Wales. Respir Med 2010; 104: 981-985.

8 Chang AB, Robertson CF, van Asperen PP, et al. A multicenter study on chronic cough in children: burden and etiologies based on a standardized management pathway. Chest 2012; 142: 943-950.

9 Gupta S, Siddiqui S, Haldar P, et al. Qualitative analysis of high-resolution CT scans in severe asthma. Chest 2009; 136: 1521-1528.

10 Chang AB, Byrnes CA, Everard ML. Diagnosing and preventing chronic suppurative lung disease and bronchiectasis. Paediatr Respir Rev 2011; 12: 97-103.

1 Valery PC, Morris PS, Byrnes CA, et al. Long-term azithromycin for Indigenous children with non-cysticfibrosis bronchiectasis or chronic suppurative lung disease (Bronchiectasis Intervention Study): a multicentre, doubleblind, randomised controlled trial. Lancet Respir Med 2013; 1: 610-620.

12 Chang AB, Bell SC, Torzillo PJ, et al; and the extended voting group. Clinical guideline. Chronic suppurative lung disease and bronchiectasis in children and adults in Australia and New Zealand. Thoracic Society of Australia and New Zealand. http://www.thoracic.org.au/imagesDB/wysiwyg/ BEposstatement_2014_revised_TSANZ_website_v3_wrFINAL. pdf (accessed Dec 2014).

13 Guyatt GH, Oxman AD, Kunz R, et al. Going from evidence to recommendations. BMJ 2008; 336: 1049-1051. 